\title{
Interrogating Vitality of the Streets in two Cypriot Towns
}

\author{
Siavash Jalaladdini, Derya Oktay \\ Department of Architecture, \\ Eastern Mediterranean University, Famagusta, North Cyprus, via Mersin 10, Turkey \\ siavash.jalaladdini@gmail.com, derya.oktay@emu.edu.tr
}

\begin{abstract}
This paper focuses on the issue of vitality in urban public spaces, streets in particular, as a major indicator of their success and as one of the determinants of livable cities. The study first provides a theoretical framework for understanding the social value and role of urban public spaces in quality of urban life. Second, it discusses essential components of vitality in streets. Finally, it investigates vitality and its determinants in two main streets in Famagusta and Kyrenia, in North Cyprus. The paper highlights some issues such as proper connection and proximity to important magnets, along with physical and social attributes in the street area.
\end{abstract}

Keywords: Urban public spaces, Major streets, Vitality, North Cyprus

eISSN 2514-751X @ 2018. The Authors. Published for AMER ABRA CE-Bs by e-International Publishing House, Ltd., UK. This is an open access article under the CC BY-NC-ND license (http://creativecommons.org/licenses/bync-nd/4.0/). Peer-review under responsibility of AMER (Association of Malaysian Environment-Behaviour Researchers), ABRA (Association of Behavioural Researchers on Asians) and cE-Bs (Centre for EnvironmentBehaviour Studies), Faculty of Architecture, Planning \& Surveying, Universiti Teknologi MARA, Malaysia.

DOI: https://doi.org/10.21834/aje-bs.v3i7.264 


\subsection{Introduction}

Public spaces have been a central concern of urban planners for centuries since the management of Greek agora and Roman forum. However, they have been neglected for a long time due to the effects of modern urban planning trends. In the modernist planning approach which has been influential all over the world cities in the last 50 years, the focus has been on the requirements of cars rather than the needs and expectations of pedestrians. Therefore, cities have lost many qualities that they used to have in the older precedents. This has negatively affected the liveability in cities (Oktay, 1990). Vitality as the concept that distinguishes successful urban spaces from the others is lacking in many contexts.

In line with these, this study aims to understand the meaning and use of urban public space, analyse its social values and influence on the quality of urban life. It investigates the degree of vitality in two major streets in Famagusta and Kyrenia, two cities in North Cyprus.

\subsection{Literature Review}

\section{Understanding Urban Public Spaces and their Social Value}

Almost all definitions and views about public space include the primary indicators of accessibility and activity (Kostof, 1993, Tibbalds, 1992, Carr et al. 1992). In a generalized view, urban public space is a space within the city area which is accessible to all people and is a ground for their activities. According to Madanipour's (1996) terms: "they are controlled by a public agency and are provided and managed in the public interest". Urban public spaces could be analysed in two major forms: (a) streets; (b) squares (Moughtin, 1996).
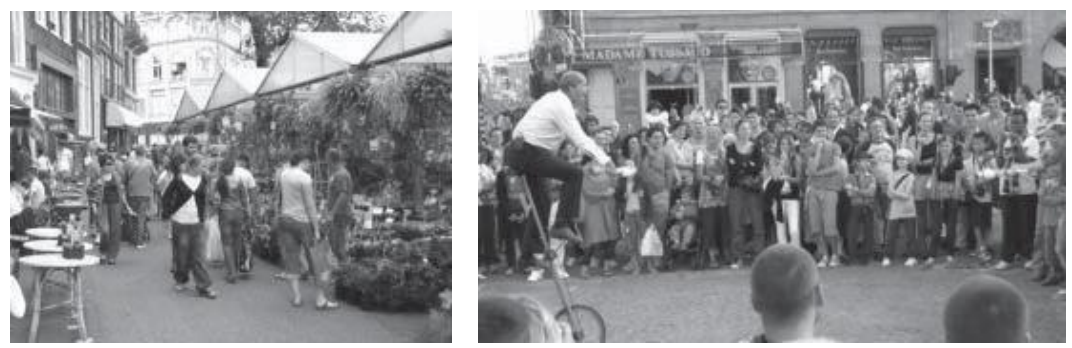

Figure 1a: Daily Activities in a Street in Amsterdam;

$1 \mathrm{~b}$ : Periodic Festivities and Events in a Plaza in Amsterdam

People's public life occurs in urban public spaces in a complex set of forms and functions; accordingly, these spaces must be capable to contain diverse behaviour, uses and activities (Fig. 1a \& 1b). As Montgomery (1998) emphasizes, "it is the public realm and associated semi-public spaces which provide the terrain for social interaction". In modernist urban planning, considerable attention is on requirements of cars rather than pedestrians' needs. However, human beings are central to urban design and an efficient pedestrian activity is more important to provide vitality in urban areas rather than vehicular circulation 
(Oktay, 2002; Jacobs, 1994; Montgomery, 1998). The declining approach during the modern period has affected many urban areas and transformed them into inhuman spaces which reduce the liveability in cities. In Cyprus, there are many newly introduced streets in urban areas that are being utilized as movement channels for cars rather than as comfortable areas for pedestrians. Moreover, their social role is being ignored. However, some streets are still working as vibrant and dynamic spaces in both the historic areas and the new ones. This paper explores the socio-spatial relations in two vibrant streets in two important towns of North Cyprus.

\section{Vitality in Streets}

Vitality is one of the performance dimensions of urban design (Lynch, 1981) and concerned with the degree with which an urban space is socially successful while is providing a satisfactory visual quality in the environment. According to the Montgomery's (1998) definition, it refers to the number of people in and around the street at the various instants of day and night time, the uptake of facilities, the number of cultural events and celebrations per year, the presence of an active street life and the extent to which a place feels alive or lively.

It should be noted that a more appropriate design of a public space satisfies more needs of the people. Meeting people's needs and adapting to their activities is then a key objective of a good public space. Maslow pyramid of needs which is now a widely accepted concept, defines levels of needs starting from physical needs as the lowest level up to more complex needs such as social ones. In line with these, the following could be accepted as the mostimportant social elements of a public realm: accessibility, equity and safety.

\subsection{METHODOLOGY}

This paper draws on the findings of a case study which involves deskwork, fieldwork, and interviews methods of studying with a qualitative approach in data collection. The data collection method of the research is a mixed method consisting document survey, on-site observations, in-depth interviews with people and questionnaires. The measures of analysis include social attributes i.e. user types, social groups, variety of activities, active times, interactions and safety, and also physical attributes i.e. physical forms, amenity of the street space, and variety of the functions within the street.

\section{Case 1: Salamis Street (Famagusta)}

Salamis Street is the commercial strip of Famagusta town. This town with a harbor, a historic core and a big university is the second largest town in North Cyprus. In this study, owing to the huge length of the street, the northern part of the street extending from Toros Roundabout to EMU campus was selected (Fig. 2). This would also lead us to a more coherent result as the southern part has different characteristics and meaning.

Salamis Street can be considered the most vital public space in the town due to the presence of people over different times of the day and year. However, despite the variety of 
functions along the street, there are serious limitations on the general quality of the environment. As highlighted by Oktay (2005), there are incompatible land-uses and the "commercial and recreational units foster traffic congestion and increase the need for parking facilities and infrastructure. In addition to these, the urban fabric in these areas is problematic because of the unused building plots".

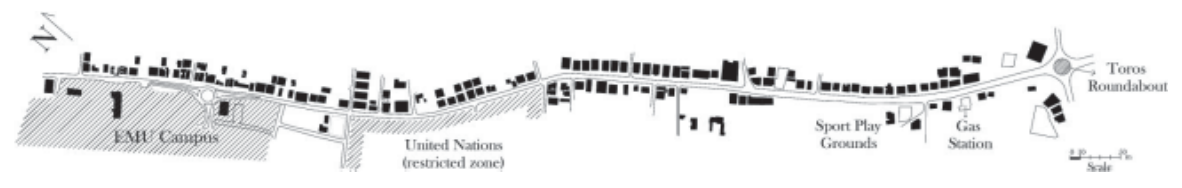

Figure 2: Salamis Street

\section{Types of the users, activities and usage of the street}

Direct connection of Salamis Street to the EMU campus makes it a walking path for students to reach their homes, using its dining venues and shopping facilities. Moreover, students use the street just to go to, walk and spend time, individually or in a group from morning to midnight. Other people use it too, as some live nearby or have work places along it, but never as much as the students do. Therefore, the majority of the users are the youth. Tourists do not constitute a large percentage of users. The elderly and children are not present in the street environment as there is a lack of facility for them. Almost mixed types of genders walk and use the street.

The mixed-use apartment buildings along the street contain a variety of functions, namely; restaurants and cafes, boutiques, markets, pharmacies, electronic shops, and betting clubs in their ground floors. However, there are numerous examples of incompatible uses in the street, i.e. car wash center and gas stations which are not compatible with the rest of the functions. The restaurants and cafes here are the students' most popular recreational facilities in the town. Unfortunately, it is impossible to spend time or have a rest unless sitting at cafes and eateries and buying stuffs (Fig. 3a). In mornings and afternoons, there is a feeling of work atmosphere and the street serves as the school path, and the commercial functions serve the customers. Work places such as banks, offices and agents perform their activities and transactions. However, social interactions are still observable (Fig. $3 b)$. In the evenings, the street has a new face getting more vibrant and attractive. Cafes and restaurants are the most crowded and the whole street serves as a place for leisure (Fig. 3c). However, as shopkeepers mentioned, depending on the season, this alters from the early evening to late evening. In this survey, the majority of the interviewees $(69 \%)$ use the street mainly for its cafes and restaurants, and one-third (31\%) uses its shops. 


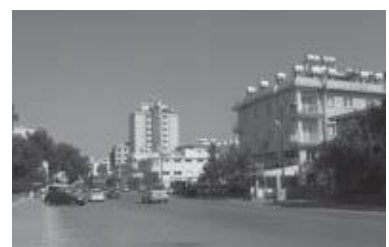

(a)

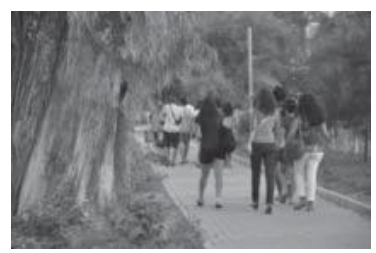

(b)

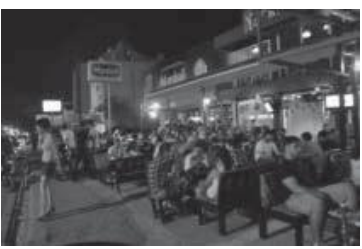

(c)

Figure 3: (a) General view of Salamis Street; (b) Students' Walk to the University in Salamis Street during Day Time; (c) Vibrant Environment of Salamis Street at Night

\section{General evaluations on salamis street}

Salamis Street is not a planned and designed public space, largely owing to the fact that Famagusta town lacks a master plan. Safety is a positive attribute of the town and its spaces. The majority of people (69\%) who participate in the survey believed that the street is safe during the day, and $76 \%$ agreed that the street is safe at night time. Amenity as another important basis of vital spaces does not properly exist in this street space. Table 1 exhibits main problems of the street space based on the observations and the participants' opinions.

Table 1: Physical Problems of Salamis Street on People Opinion

\begin{tabular}{|l|l|l|}
\hline The problems & Level of the problem & $\begin{array}{l}\text { Percentage of people } \\
\text { suffering from this problem }\end{array}$ \\
\hline Inefficient sidewalks & High & 96.6 \\
\hline Lack of bicycle path & High & 72.4 \\
\hline Lack of public transportation facilities & Medium-high & 62.1 \\
\hline $\begin{array}{l}\text { Poor quality of architecture and lack of } \\
\text { magnet buildings }\end{array}$ & Medium & 51.7 \\
\hline Lack of street lighting & Medium & 51.7 \\
\hline High speed traffic & Medium & 48.3 \\
\hline $\begin{array}{l}\text { Lack of maintenance } \\
\text { (Pollution, dirt...) }\end{array}$ & Medium & 41.4 \\
\hline Lack of outdoor spaces for gathering & Medium & 41.4 \\
\hline
\end{tabular}

\section{Case 2: Ziya Rızkı Street (Kyrenia)}

Ziya Rızkı Street is the main commercial strip of Kyrenia town. Kyrenia is the third largest town in North Cyprus with an antique harbor and a small university, and the center of the country's tourist industry and commerce. As the town lacks a well defined and active central space (a square), it can be considered the center of the town and accommodates numerous cafes, eateries, hotels and casinos which help create vitality during the day and at 
night. In this study, the northern part of the street extending from Ramadan Cemil Roundabout to Tourism Park was selected since it reflects more intensive public use and meaning comparing to thesouthern part (Fig. 4).

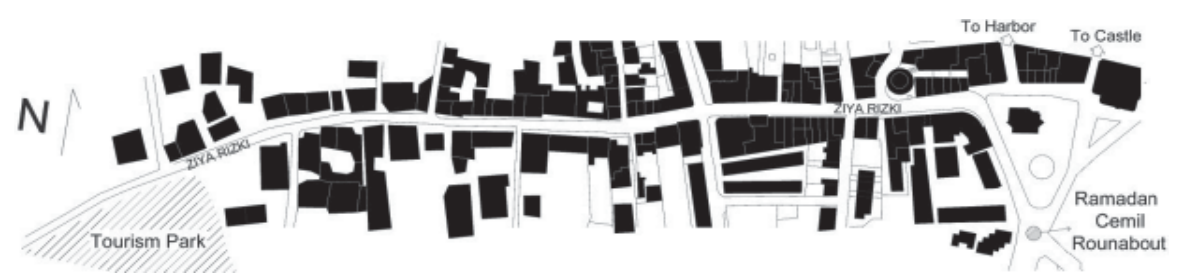

Figure 4: Ziya Rızkı Street, Kyrenia

\section{Type of the users, activities and usage of the street}

Owing to its proximity to the harbor and the traditional core, Ziya Rızkı Street provides an excellent shopping opportunity to the visitors while visiting the harbor and historical places. Observations reveal that people of different age, gender and nationality use this street. Two main users of this street are tourists and students while other citizens are rarely seen (Fig. 5a). The Street offers limited facilities for the daily needs of local citizens. Observations on social groups on the street show that the family groups are the dominant social groups there (Fig. 5b). The street space is not a place for stopping and sitting for a while - except at the beginning of the street by the Municipality Building where one can sit on benches - but has a lively atmosphere that consists of several types of people window shopping and moving with exploring eyes.
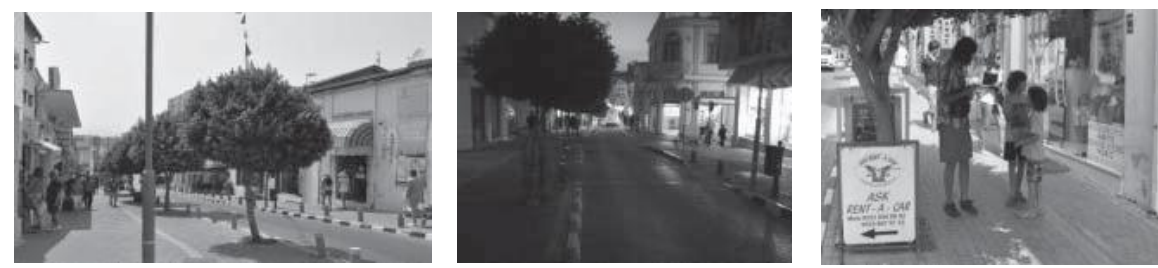

Figure 5(a): Vibrant Milieu of Ziya Rızkı Street during Day Time; (b) Family Groups as the Major Social Group at Ziya Rızkı Street; (c) Silent Atmosphere of Ziya Rızkı Street at Night

This arrangement makes this street a more shopping type, which is alive while the shops are open, and it gets quiet after the closing time. The majority of the interviewees $(58.6 \%)$ shop in this street and less than half $(37.9 \%)$ enjoy the cafes and restaurants, while only a minor population (3.4\%) use the casinos and betting clubs.

\section{General evaluations on ziya rızkı street}

The street has especial location being almost at the center of the town with good 
connections to the other parts of the town, the harbor and the historic quarter. The area is safe like the other quarters of the town. Mainly one and two stories historic building provide the streets edges which enclose the street space. It has a human scale environment. However, its capacity is limited to one-way traffic due to its short width. The major problems in the street spaces were classified according to the observations and the users' opinions as listed in Table 2.

Table 2: Physical Problems of Salamis Street in People's

\begin{tabular}{|l|l|l|}
\hline The problems & $\begin{array}{l}\text { Level of the } \\
\text { problem }\end{array}$ & $\begin{array}{l}\text { Percentage of people } \\
\text { suffering from this } \\
\text { problem }\end{array}$ \\
\hline Inefficient sidewalks & High & 72.4 \\
\hline Lack of street lightening & Medium & 51.7 \\
\hline Pollution and dirt & Medium & 48.3 \\
\hline Lack of public transportation facilities & Medium & 44.8 \\
\hline Lack of sense of safety at night time & Medium & 41.4 \\
\hline
\end{tabular}

\section{Comparison between the two cases}

There is no hesitation in indicating "vitality" as the common attribute of the two streets. The systematic comparison was carried out while concentrating on the following items: user types, social groups, activities and interactions, and the time of activities on the street.

The reasons of vitality are different in the two streets. Presence of visitors and tourists provide vitality in Ziya Rızkı while university students are the main reason for vitality in Salamis street. In Salamis Street, the communal way of use and daily engagement of the users make the social atmosphere friendlier. Vice versa, the users in Ziya RIzkı Street do not engage in the street space daily since they are mostly visitors. The shops are the magnets in Ziya Rızkı Street. As such, walking, shopping or window shopping are the main activities in the street. Using the eateries and cafes is more obvious than shopping contrary to Ziya Rızkı Street. Salamis is alive from early morning. The most vital time is in evenings and at nights. However, Ziya Rızkı is only alive from late morning up to the evening times. The most vibrant times in Ziya Rızkı are late mornings and evenings. Table 3 summarized these similarities and differences between the two streets.

Table 3: Determinants of Vitality in the Two Streets.

\begin{tabular}{|l|l|l|}
\hline $\begin{array}{l}\text { The items of } \\
\text { comparison }\end{array}$ & Salamis St. & Ziya Rızk St. \\
\hline Dominant user type & Students & Tourists \\
\hline Dominant social group & Friend groups & Family groups \\
\hline
\end{tabular}


Jalaladdini, S. \& Oktay, D. / Asian Journal of Environment-Behaviour Studies (ajE-Bs), 3(7) Mar / Apr 2018 (p.119-127)

\begin{tabular}{|l|l|l|}
\hline Dominant activities & $\begin{array}{l}\text { Using the restaurants, cafes \& } \\
\text { bars }\end{array}$ & $\begin{array}{l}\text { Shopping or window } \\
\text { shopping }\end{array}$ \\
\hline Time of activities in the street & $\begin{array}{l}\text { From early morning to late } \\
\text { night }\end{array}$ & $\begin{array}{l}\text { From late morning to } \\
\text { evening }\end{array}$ \\
\hline $\begin{array}{l}\text { The most vital time of the } \\
\text { street }\end{array}$ & $\begin{array}{l}\text { From early evening to late } \\
\text { times at night }\end{array}$ & $\begin{array}{l}\text { Late mornings \& } \\
\text { evenings }\end{array}$ \\
\hline
\end{tabular}

\subsection{Conclusion}

Public spaces affect people's quality of life and liveability in cities. They have to ensure a variety of uses at different times by a variety of users in order to be inclusive. Vitality relates to various dimensions of public space including both physical and social aspects. Streets, which have been reduced to 'traffic channels' in modernist city planning, have the potential to be transformed into vibrant and vital public spaces, and encourage liveability in cities.

The analysis of the Salamis Street in Famagusta and the Ziya Rızkı Street in Kyrenia as the most vital streets in these towns shows how they work socially. The study shows that, although the presence of people is evident in both cases, the determinants of vitality in each are different. Salamis is vital owing to the presence of the students of the university while in Ziya Rızkı visitors and tourists are the main users that make the area vibrant, moreover, the duration of the uses vary significantly. It can then be concluded that not all vital public spaces have the same reasons behind, and any design and management related to a public space should be pursued through area-based work where the peculiarities of the specific place are taken into consideration.

\section{References}

Carr et al. (1992). Public Space. Cambridge: Cambridge University Press. Jacobs, J. (1994). The Death and Life of GreatAmerican Cities. New York:Modern

Library.

Kostof, S. (1993). The City Assembled. London: Thames and Hudson. Lynch, K. (1981). Good City Form. Cambridge: MIT Press.

Madanipour, A. (1996). Notes from Design of Urban Space, an Inquiry into a Socio-spatial Process. England: Wiley (John Wiley \& Sons Ltd).

Montgomery, J. (1998). Making a city: urbanity, vitality and urban design. Journal of Urban Design, 3: 1, 93-116.

Moughtin, C. (1996). Urban Design; Street and Square. Oxford: Butterworth Architecture.

Oktay, D. (2005). "Cyprus: the South and the North", in Urban Issues and Urban Policies in the New EU countries (Eds: R.Van Kempen, M. Vermeulen \& A. Baan), Aldershut: Ashgate, 205-231.

Oktay, D. (2002). "The Quest for Urban Identity in the Changing Context of the City: Northern Cyprus, Cities, 19: 4, 31-41. 
Jalaladdini, S. \& Oktay, D. / Asian Journal of Environment-Behaviour Studies (ajE-Bs), 3(7) Mar / Apr 2018 (p.119-127)

Oktay, D. (1996). Notes on Urban Design. Famagusta: EMU Press.

Tibbalds, F (1992). Making People-friendly Town, Improving the Public Environment in Town and Cities. Harlow, Longman. 